\title{
Prevalence and Predictors of Caregiver Burden in a Memory Clinic Population
}

\author{
Rónán O’Caoimh ${ }^{\mathrm{a}, \mathrm{b}, \mathrm{c}, *}$, Mareeta Calnan $^{\mathrm{a}}$, Arup Dhar ${ }^{\mathrm{d}, \mathrm{e}}$ and D. William Molloy ${ }^{\mathrm{a}}$ \\ ${ }^{a}$ Centre for Gerontology and Rehabilitation, University College Cork, St Finbarr's Hospital, Cork City, Ireland \\ ${ }^{\mathrm{b}}$ Health Research Board, Clinical Research Facility Galway, National University of Ireland, Galway, Ireland \\ ${ }^{\mathrm{c}}$ Department of Geriatric Medicine, Mercy University Hospital, Grenville Place, Cork City, Ireland \\ ${ }^{\mathrm{d}}$ Baker Heart and Diabetes Institute, Melbourne VIC, Australia \\ ${ }^{\mathrm{e}}$ NeuroCentrix, Noble Park, VIC, Australia
}

Accepted 10 August 2021

Pre-press 3 September 2021

\begin{abstract}
.
Background: Although caregiver burden is common among carers of people with dementia, little is known about its prevalence and predictors among caregivers of patients attending memory clinics.

Objective: To examine carer and patient-specific characteristics associated with caregiver burden across the cognitive spectrum in a memory clinic population.

Methods: Consecutive patients referred to a university hospital geriatric memory clinic were included. Caregiver burden was scored using the Caregiver Burden Score (CBS), (modified Zarit), with scores $\geq 15 / 30$ suggesting burden. BPSD were measured with the dysfunctional behaviour rating instrument (DBRI). Cognition was screened using the Montreal Cognitive Assessment (MoCA) and Quick Mild Cognitive Impairment (Qmci) screen.

Results: In all, 351 patients were included, median age $77( \pm 11)$ years; $65.5 \%$ were female. The prevalence of caregiver burden was $33.6 \%$ overall, increasing from $10.8 \%$ in subjective cognitive decline (SCD), to $15 \%$ in mild cognitive impairment (MCI) and $43 \%$ in dementia; CBS scores were significantly higher in dementia $(p<0.001)$. Caregivers with burden were significantly younger $(p=0.045)$ and were more likely to be adult children $(p=0.007)$. The CBS weakly correlated with the stage of cognitive impairment $(r=0.16)$ but had moderate correlation with MoCA $(r=-0.54)$ and Qmci scores $(r=-0.60)$. After adjustment for co-variates, DBRI scores alone independently predicted burden (odds ratio $1.23 ; 1.11-1.35, p<0.001$ ). Conclusion: Caregiver burden is associated with the stage of cognitive impairment, with higher prevalence proportions in those with dementia compared with MCI and SCD. Only the severity of neuropsychiatric symptoms independently predicted caregiver burden in this population and its presence should prompt assessment for burden.
\end{abstract}

Keywords: Caregiver burden, carers, dementia, memory clinic, mild cognitive impairment, predictors, prevalence

\section{INTRODUCTION}

Providing care for people with cognitive impairment including dementia is challenging. Care is

\footnotetext{
*Correspondence to: Dr. Rónán O’Caoimh, MB, MSc, MPH, $\mathrm{PhD}$, Department of Geriatric Medicine, Mercy University Hospital, Cork, Ireland. Tel.: +00353 21420 5976; E-mails: rocaoimh@hotmail.com or rocaoimh@muh.ie; ORCID ID: 00000002-1499-673X
}

associated with increased all-cause mortality among caregivers [1] as well as depression [2], anxiety [3], stigma [4], and lower quality of life [5]. As this is underappreciated at a societal level, caregivers are often referred to as the "hidden victims" of dementia [6]. Caregiver burden is common with a recent meta-analysis suggesting that up to half (pooled estimate of $49 \%$ ) of informal caregivers of people with dementia are affected, albeit with marked 
heterogeneity between studies, particularly in terms of setting [7]. Important factors associated with selfreported caregiver burden among those managing the care of people with dementia include higher levels of functional impairment and more advanced cognitive decline [8]. Other commonly reported factors include female sex, being older and socially isolated [7, 9]. Caregivers with more experience, providing care for fewer hours and with greater support available have lower levels of burden [10].

Caregiver burden among care providers of those attending memory clinics is less studied but also considered common. Up to half of carers of people with dementia in one study in Australia reported burden, with rising rates over time [11]. In dementia, burden is also strongly associated with concerns over safety and difficulty managing the behavioural and psychological symptoms of dementia (BPSD) [12]. At earlier stages of cognitive impairment, before onset of functional decline such as mild cognitive impairment (MCI), caregiver burden is also reported, though few studies have examined burden in this population or compared it to those with subjective cognitive decline (SCD) or established dementia [13]. Of the studies available, between $20-36 \%[14,15]$ of carers of people with MCI report burden.

To date, few studies have examined the prevalence and predictors of burden in caregivers of people with dementia attending memory clinics [7], particularly its relationship with cognitive test scores, comparing those with different stages of decline. One recent study reported a prevalence of burden among carers of people with MCI of between 21.1-29.5\% over three years in Australia [16]. Further, it is not known if the results of short cognitive screening instruments (CSI) are useful in predicting those likely to have caregiver burden to help prompt the need for assessment. Better understanding of caregiver burden among those providing care to patients attending memory clinics may help inform interventions to enhance both carer and patient outcomes [4]. Given these points we aimed to:

1) Establish the prevalence by stage of cognitive impairment to establish the prevalence of caregiver burden in an Irish memory clinic population across the spectrum of cognitive decline from SCD to MCI and dementia.

2) Examine and compare and contrast both caregiver and patient-specific characteristics associated with burden among those presenting to an Irish memory clinic to investigate factors associated with caregiver burden in this setting.

3) Assess if the results of short CSIs can help predict those likely to have caregiver burden in this population and to evaluate if the stage of cognitive impairment or individual cognitive scores are useful predictors in memory clinics.

\section{METHODS}

The methods for this secondary analysis of a cross-sectional study (diagnostic accuracy study comparing cognitive screening instruments) have been reported elsewhere [17]. In summary, consecutive patients with cognitive symptoms referred to a university hospital geriatric medicine memory clinic between March 2012 and December 2014 were included. Attending caregivers, where available, were asked to participate. A consultant geriatrician using established criteria determined diagnosis and stage. Dementia was classified using the Diagnostic and Statistical Manual of Mental Disorders revised 4th-edition [18] and the stage was correlated to the Reisberg FAST scale [19]. MCI was diagnosed using Petersen's criteria [20] according to the National Institute on Aging-Alzheimer's Association workgroup diagnostic guidelines [21]. SCD was defined as subjective non-progressive memory loss among those without objective cognitive deficits or functional decline, who scored either 'poor' or 'fair' on a five-point Likert scale in response to the question "how is your memory?" [22]. Those without an available or required caregiver, those with recent delirium and active depression, aged less than 45 , declining consent, with an unclear diagnosis, missing data or unable to communicate in English were excluded. All patients and caregivers provided informed written consent. Where capacity was deemed by the principal investigator to be unclear or lacking, assent was obtained. Ethics approval was granted in advance of the study from the Clinical Research Ethics Committee of the Cork Teaching Hospitals on 23 March 2012 (Reference ECM 4 aa 03/04/12).

\section{Outcomes}

Caregiver burden was scored using the Caregiver Burden Score (CBS) [23], a modified version of the Zarit Burden Interview (ZBI). The CBS is composed of six questions and describes the degree to which caring affects the caregiver from 0 (none of the time) to 6 (all of the time). Scores of $\geq 15 / 30$ were classified 
as caregiver burden. CBS scores were scored on the patients first presentation to clinic. Additional caregiver data were obtained from the Quick Memory Check, a caregiver-administered questionnaire provided in advance of the clinic appointment [24]. This provided data on each carer's relationship with the patient as well as their age, sex, education, occupation, and the number of days they provided care.

Depression among patients was screened with the GDS short-form [25], taking a higher cut-off point of $\geq 7$ to optimize specificity [26]. Functional level was based upon clinical history and examination supported by the 20-point Barthel Index (BI) [27] and a modified version of the Lawton-Brody activities of daily living scale (ADL) [28]. Unless there was co-existing physical disability, the BI measures basic ADL and is scored from functional independence in these ADL (20/20) to full dependence $(0 / 20)$. The modified Lawton-Brody ADL scale includes both instrumental and basic ADL. It has 10 subtests, scored by informants: medications, finances, telephone use, food preparation, grooming, bathing, walking, toileting (urine/feces), transferring and feeding themselves. Each subtest has two questions: what is the level of care required, and how much of a problem is this. Each subtest is scored from zero to four, with higher scores suggesting greater dependency. BPSD were assessed using a modified version of the Neuropsychiatric Inventory [29]. This dysfunctional behaviour rating instrument (DBRI) scores severity (frequency) over the preceding week for the 12 items on a Likert scale from 0 (never) to 5 (more than five times a day) giving a total score of 60 points with higher scores indicating greater BPSD [30].

Two short cognitive screening instruments were scored independent of the diagnosis of cognitive impairment, the Montreal Cognitive Assessment (MoCA) [31] and Quick Mild Cognitive Impairment (Qmci) screen [32, 33]. The MoCA is a well-established short cognitive screen with high sensitivity for detecting MCI with seven subtests covering five cognitive domains; memory, language, visuospatial, attention and cognitive control, scored out of 30 points. The Qmci screen is a newer short cognitive screen designed to differentiate MCI from early dementia and normal cognition with six subtests covering five domains: orientation, registration, clock drawing, delayed recall, verbal fluency, and logical memory (immediate verbal recall of a short story), scored out of 100 points. For both cognitive screens, lower scores indicate cognitive impairment with cut-off scores varying by the sample assessed.

\section{Data collection}

Patients underwent a comprehensive work-up for memory loss including history, physical examination, laboratory testing, and neuroimaging. A short battery of tests including the Standardized Mini-Mental State Examination (SMMSE) [34], the AD8 questionnaire [35] and the widely-used observer rated IQCODE Short Form [36] were conducted by a consultant geriatrician independent of the screening tests to inform the diagnosis. The CBS and measures of mood, function and BPSD were administered by trained clinic nurses.

\section{Analysis}

Data were analysed using SPSS 22.0 (Chicago, IL, USA) and R version 3.5.0 (2018-04-23) -“Joy in Playing" (R Core Team, 2018). Normality was tested using the Shapiro-Wilk test. The majority of the data were non-normally distributed and were analysed using non-parametric approaches. The data were correlated with Spearman's rho. The Mann-Whitney $U$ test compared median values and the Kruskal-Wallis test was used for comparisons between more than two groups. Binary logistic regression was used to examine the association between variables using the Enter method. Carer relationship was dichotomized into spouse or other relative, occupation into employed versus not currently employed and educational level was dichotomized into those completing third level (higher/university) education versus those with lower levels of education.

\section{RESULTS}

In total, 351 patients were available and included in the analysis. Their median age was $77(\mathrm{IQR} \pm 11)$ years and $65.5 \%$ were female. Of these, most $(67 \%)$ had dementia $(n=235)$. The remainder had MCI $(n=79)$ and SCD $(n=37)$. The majority $(73 \%)$ had mild stage dementia $(n=171)$. The prevalence of caregiver burden overall was $33.6 \%$. This increased from $10.8 \%$ in SCD, to $15 \%$ in MCI and $43 \%$ in dementia. The CBS weakly correlated with diagnostic category $(r=0.16, p=0.001)$ and participant age $(r=0.22, p<0.001)$ but had moderate correlation with MoCA $(r=-0.54, p<0.001)$ and Qmci screen scores $(r=-0.60, p<0.001)$. As expected, median CBS scores were significantly higher among caregivers of people with dementia compared with MCI and SCD (median scores of 13 versus 6 versus 0 , 
Table 1

Characteristics of participants including Caregiver Burden Scores (CBS), Montreal Cognitive Assessment (MoCA), and Quick Mild Cognitive Impairment $(\mathrm{Q} m \mathrm{ci})$ screen scores according to each of the diagnostic categories

\begin{tabular}{|c|c|c|c|c|c|c|}
\hline Variable & $\begin{array}{c}\text { Subjective } \\
\text { Cognitive } \\
\text { Disorder } \\
(n=37) \\
\end{array}$ & $\begin{array}{c}\text { Mild } \\
\text { Cognitive } \\
\text { Impairment } \\
(n=79) \\
\end{array}$ & $\begin{array}{c}\text { All } \\
\text { Dementia } \\
(n=235)\end{array}$ & $\begin{array}{c}\text { Mild } \\
\text { Dementia } \\
(n=171)\end{array}$ & $\begin{array}{c}\text { Moderate } \\
\text { Dementia } \\
(n=53)\end{array}$ & $\begin{array}{c}\text { Severe } \\
\text { Dementia } \\
(n=11)\end{array}$ \\
\hline Age & & & & & & \\
\hline $\begin{array}{l}\text { Median } \\
(\mathrm{Q} 3-\mathrm{Q} 1 \pm \mathrm{IQR}) \\
\text { Sex }\end{array}$ & $71(78-65= \pm 13)$ & $76(81-68= \pm 13)$ & $77(82-72= \pm 10)$ & $77(82-73= \pm 9)$ & $79(83-68= \pm 15)$ & $77(79-68= \pm 11)$ \\
\hline $\begin{array}{l}\% \text { Female } \\
\text { Carer }\end{array}$ & $53 \%$ & $65 \%$ & $68 \%$ & $69 \%$ & $69 \%$ & $58 \%$ \\
\hline $\begin{array}{l}\text { Burden } \% \geq 15 / 30 \\
\text { CBS }\end{array}$ & $10.8 \%$ & $15 \%$ & $43 \%$ & $39 \%$ & $55 \%$ & $64 \%$ \\
\hline $\begin{array}{l}\text { Median } \\
\text { (Q3-Q1 } \pm \text { IQR) } \\
\text { DBRI }\end{array}$ & $0(4-0= \pm 4)$ & $6(11-0= \pm 11)$ & $13(20-6= \pm 14)$ & $12(19-4= \pm 15)$ & $16(22-10= \pm 12)$ & $19(21-14= \pm 7)$ \\
\hline $\begin{array}{l}\text { Median } \\
(\mathrm{Q} 3-\mathrm{Q} 1 \pm \mathrm{IQR}) \\
\text { MoCA }\end{array}$ & $1(3-0= \pm 3)$ & $6(8-3= \pm 5)$ & $10(16-6= \pm 10)$ & $9(13-5= \pm 8)$ & $13(20-9= \pm 11)$ & $20(29-10= \pm 19)$ \\
\hline $\begin{array}{l}\text { Median }(\mathrm{X} / 30) \\
(\mathrm{Q} 3-\mathrm{Q} 1 \pm \mathrm{IQR}) \\
\mathrm{Q} m c i \text { screen }\end{array}$ & $25(27-23= \pm 4)$ & $22(25-20= \pm 5)$ & $13(17-8= \pm 15)$ & $16(19-12= \pm 7)$ & $6(9-3= \pm 6)$ & $2(4-0= \pm 4)$ \\
\hline $\begin{array}{l}\text { Median }(\mathrm{X} / 100) \\
(\mathrm{Q} 3-\mathrm{Q} 1 \pm \mathrm{IQR})\end{array}$ & $68(73-63= \pm 10)$ & $59(64-52= \pm 12)$ & $37(45-22= \pm 23)$ & $41(46-32= \pm 14)$ & $17(26-9= \pm)$ & $7(9-3= \pm 6)$ \\
\hline
\end{tabular}

Table 2

Predictors of Caregiver Burden for patients according to the Caregiver Burden Score (CBS) including Montreal Cognitive Assessment (MoCA) and Quick Mild Cognitive Impairment $(\mathrm{Q} m c i)$, comparing those with $(\mathrm{CBS} \geq 15)$ and without $(\mathrm{CBS}<15)$ caregiver burden

\begin{tabular}{|c|c|c|c|c|}
\hline Variable & $\begin{array}{l}\text { All Participants } \\
\quad(n=351)\end{array}$ & $\begin{array}{l}\mathrm{CBS} \geq 15 \\
(n=118)\end{array}$ & $\begin{array}{l}\text { CBS }<15 \\
(n=233)\end{array}$ & $p=\mathrm{X}$ \\
\hline \multicolumn{5}{|l|}{ Age - Patient } \\
\hline Median (Q3-Q1 \pm IQR) & $77(81-70= \pm 11)$ & $79(83-73= \pm 10)$ & $76(80-70= \pm 10)$ & $p=0.001$ \\
\hline Sex & & & & \\
\hline$\%$ Female & $65.5 \%$ & $66 \%$ & $65 \%$ & $p=0.91$ \\
\hline \multicolumn{5}{|l|}{ Barthel Index } \\
\hline $\begin{array}{l}\text { Median (Q3-Q1 } \pm \mathrm{IQR}) \\
\text { Geriatric Depression Scale }\end{array}$ & $20(20-20= \pm 0)$ & $18(20-15= \pm 5)$ & $20(20-20= \pm 0)$ & $p<0.001$ \\
\hline $\begin{array}{l}\text { Median (Q3-Q1 } \pm \text { IQR) } \\
\text { DBRI }\end{array}$ & $0(2-0= \pm 2)$ & $1(2-0= \pm 2)$ & $1(2-0= \pm 2)$ & $p=0.43$ \\
\hline $\begin{array}{l}\text { Median (Q3-Q1 } \pm \text { IQR) } \\
\text { MoCA }\end{array}$ & $8(13-4= \pm 9)$ & $13.5(20-9= \pm 11)$ & $6(10-3= \pm 7)$ & $p<0.001$ \\
\hline $\begin{array}{l}\text { Median }(\mathrm{Q} 3-\mathrm{Q} 1 \pm \mathrm{IQR}) \\
\text { Qmci screen }\end{array}$ & $20(25-13= \pm 12)$ & $13(19-7= \pm 12)$ & $19(23-13= \pm 10)$ & $p<0.001$ \\
\hline $\begin{array}{l}\text { Median }(\mathrm{Q} 3-\mathrm{Q} 1 \pm \mathrm{IQR}) \\
\text { Subiective Coonitive Decline }\end{array}$ & $51(68-36= \pm 32)$ & $36(47-21= \pm 26)$ & $47(61-37= \pm 24)$ & $p<0.001$ \\
\hline $\begin{array}{l}\% \text { Diagnosis } \\
\text { Mild Cognitive Impairment }\end{array}$ & $10.5 \%$ & $10.8 \%$ & $89.2 \%$ & $p<0.001$ \\
\hline $\begin{array}{l}\text { \% Diagnosis } \\
\text { Dementia }\end{array}$ & $22.5 \%$ & $15 \%$ & $85 \%$ & $p<0.001$ \\
\hline$\%$ Diagnosis & $67 \%$ & $88 \%$ & $57 \%$ & $p<0.001$ \\
\hline
\end{tabular}

respectively, $p<0.001)$. Among those with dementia, patients with severe dementia (median 19) had statistically significantly higher CBS scores than those with either mild (median 12) or moderate (median 16) dementia $(p=0.002)$. The majority of patients had some neuropsychiatric symptoms as reported by their caregiver with only $7 \%$ of patients scoring 0 on the DBRI. Patients with dementia had significantly higher DBRI scores than those with MCI and SCD $(p<0.001)$. DBRI scores were also higher in those with more severe dementia $(p=0001)$. The characteristics of participants according to each of the diagnostic categories are presented in Table 1.

Features of patients according to CBS scores are presented in Table 2 . Those patients whose caregivers reported burden (scores $\geq 15$ ) were statistically 
Table 3

Characteristics of caregivers by diagnostic category and by association with caregiver burden comparing all three categories and those with $(\mathrm{CBS} \geq 15)$ and without $(\mathrm{CBS}<15)$ caregiver burden

\begin{tabular}{|c|c|c|c|c|c|c|c|c|}
\hline Variable & $\begin{array}{l}\text { All Participants } \\
\quad(n=351)\end{array}$ & $\begin{array}{c}\text { Subjective } \\
\text { Cognitive } \\
\text { Disorder } \\
(n=37) \\
\end{array}$ & $\begin{array}{c}\text { Mild } \\
\text { Cognitive } \\
\text { Impairment } \\
(n=79) \\
\end{array}$ & $\begin{array}{c}\text { All } \\
\text { Dementia } \\
(n=235)\end{array}$ & $p=X^{*}$ & $\begin{array}{l}\mathrm{CBS} \geq 15 \\
(n=118)\end{array}$ & $\begin{array}{l}\mathrm{CBS}<15 \\
(n=233)\end{array}$ & $p=\mathrm{X}^{* *}$ \\
\hline \multicolumn{9}{|l|}{ Age - Caregiver } \\
\hline $\begin{array}{l}\text { Median } \\
\text { (Q3-Q1 } \pm \text { IQR) } \\
\text { Sex - Caregiver }\end{array}$ & $\begin{array}{c}54 \\
(71-44= \pm 27)\end{array}$ & $\begin{array}{c}61 \\
(71-45= \pm 26)\end{array}$ & $\begin{array}{c}52 \\
(69-45= \pm 24)\end{array}$ & $\begin{array}{c}54 \\
(70-45= \pm 25)\end{array}$ & $p=0.72$ & $\begin{array}{c}51 \\
(66-41= \pm 25)\end{array}$ & $\begin{array}{c}59 \\
(73-46= \pm 27)\end{array}$ & $p=0.045$ \\
\hline $\begin{array}{l}\% \text { Female } \\
\text { Relationship }\end{array}$ & $66 \%$ & $88 \%$ & $63.5 \%$ & $66 \%$ & $p=0.06$ & $66 \%$ & $65 \%$ & $p=0.72$ \\
\hline $\begin{array}{l}\text { \% Spouse versus } \\
\text { Children/Other } \\
\text { relatives }\end{array}$ & $39 \%$ & $52 \%$ & $34 \%$ & $38 \%$ & $p=0.29$ & $26 \%$ & $45 \%$ & $p=0.007$ \\
\hline $\begin{array}{l}\text { Education level } \\
\% \text { Third level } \\
\text { Occupation }\end{array}$ & $45 \%$ & $37.5 \%$ & $50 \%$ & $45 \%$ & 0.58 & $40 \%$ & $48 \%$ & $p=0.26$ \\
\hline $\begin{array}{l}\% \text { Currently } \\
\text { employed versus } \\
\text { other } \\
\text { Days per week } \\
\text { with patient }\end{array}$ & $50 \%$ & $40 \%$ & $61 \%$ & $47 \%$ & $p=0.2$ & $44 \%$ & $53 \%$ & $p=0.31$ \\
\hline $\begin{array}{l}\text { Median } \\
(\mathrm{Q} 3-\mathrm{Q} 1 \pm \mathrm{IQR})\end{array}$ & $7(7-4= \pm 3)$ & $7(7-7= \pm 0)$ & $7(7-2= \pm 5)$ & $7(7-5= \pm 2)$ & $p=0.2$ & $7(7-5= \pm 2)$ & $7(7-4= \pm 3)$ & $p=0.85$ \\
\hline
\end{tabular}

* Comparing all three diagnostic categories (Subjective Cognitive Disorder versus mild cognitive impairment versus dementia). ** Comparing those with $(\mathrm{CBS} \geq 15)$ and without $(\mathrm{CBS}<15)$ caregiver burden.

significantly more likely to be older $(p=0.001)$, have lower BI scores $(p<0.001)$ and have higher DBRI scores $(p<0.001)$. Cognitive screen scores were also significantly lower for patients whose caregivers scored as having caregiver burden with both the MoCA and Qmci screen scores lower $(p<0.001)$. Reflecting this, a greater proportion had dementia, $88 \%$ versus $57 \%$ with either MCI or $\operatorname{SCD}(p<0.001)$.

The characteristics of caregivers in total and by the diagnostic classification of the patients they attended with and their association with CBS scores $(\geq 15$ versus $<15$ points) are presented in Table 3 . Caregivers reporting burden were significantly younger, median age 51 versus 59 years $(p=0.045)$ and were less likely to be the patients spouse $26 \%$ versus $45 \%$ for other relationships $(p=0.007)$. The sex, level of education, occupational status, and number of days spent caring did not significantly influence burden. By diagnostic category, the characteristics of carers of people with dementia and MCI did not differ significantly. Most were female, half reported completing a third-level education and described themselves as a child or other non-spouse relative. Those caring for people with dementia and MCI were younger than caregivers of those with SCD. Logistic regression adjusting for age (both patient and carer), sex, BI, GDS, DBRI, cognition (either MoCA or Qmci screen), and the relationship of the patient to the carer showed that only the patients' DBRI scores were independently associated with higher risk of caregiver burden, odds ratio 1.23 (95\% confidence interval $1.11-1.35, p<0.001)$. Examining the individual characteristics of caregivers including indirect measures of their socioeconomic status (education and current employment) found that younger age of carers was associated with increased odds of burden, but this was no longer statistically significant when DBRI scores were included in the model.

When only caregivers attending with patients diagnosed with MCI were examined in regression models, adjusting for the same variables (age of patient or carer, sex, BI, GDS, DBRI, cognition screen score, and the relationship of the patient to the carer), found that no single item was statistically significantly associated with caregiver burden.

\section{DISCUSSION}

This cross-sectional epidemiological study examining the prevalence and predictors of caregiver burden among caregivers of older Irish adults attending a university hospital memory clinic showed that burden is high among carers attending with these 
patients. The results also show that despite higher levels of burden among younger carers, caregivers of older patients and those with lower cognition and poorer functional status, the only independent predictor was the severity of BPSD as recorded by the DBRI.

\section{Epidemiological findings}

In this study the overall prevalence of caregiver burden was $33.6 \%$ and this increased with the severity of cognitive impairment from just over $10 \%$ (10.8\%) among those with SCD to $15 \%$ in MCI and $43 \%$ in dementia. To date, few studies have reported prevalence in dedicated memory clinics with most results available from randomized trials or longitudinal population-level studies [7]. The overall prevalence in dementia is similar to results from the few studies which have reported the proportion with burden among carers of patients attending a memory clinic. Of the limited number of studies available in a recent meta-analysis from 2019 [7], previous studies provided prevalence proportions which varied from $50 \%$ in Australia [11] to $68.5 \%$ in Colombia [37]. We found only one study reporting prevalence in MCI [16] and none among those with SCD.

This study is one of the first to confirm higher levels (proportions) of burden among carers of people with dementia compared to those diagnosed with SCD and MCI attending memory clinics. This suggests that CBS scores could be useful in helping to indicate the severity and likelihood of diagnosing cognitive impairment, particularly dementia. However, in a series of recent studies in the United Kingdom (UK), no difference in ZBI scores were found between these groups $[38,39]$. The authors concluded that burden scores do not reflect cognition and that the corollary must therefore be true. This difference may reflect the larger sample here, the use of a different, albeit similar and equally efficient and reliable (shortened version), burden score or that most caregivers attended with concern driven possibly by neuropsychiatric symptoms; CBS scores were obtained on the patients first presentation to clinic. Further, the UK studies were conducted in a neurologist-led rather than a geriatrician-led memory clinic, with a lower average age of participants than in the current study. That a relatively high proportion of carers of patients without MCI or dementia (i.e., those diagnosed with SCD) reported caregiver burden (prevalence proportion of $10.8 \%$ ), suggests the need to rule out caregiver depression [38], particularly as this study was conducted with an older population of both patients and caregivers who may have multiple chronic conditions, pre-disposing them to clinical depression [40].

\section{Predictors of caregiver burden}

The results reaffirm the strong evidence supporting the important role that neuropsychiatric symptoms play in caregiver distress [41]. High levels of these were found in this study with the majority of patients having at least one symptom in the week prior to attending. DBRI scores were independently associated with $23 \%$ increase in the odds of carers reporting burden after adjusting for a broad range of variables. This study also suggested that younger caregivers were more likely to report caregiver burden than older carers. This was mirrored by the higher proportion of children and other relatives who reported burden compared to spouses. While this was not an independent factor, it reflects the literature which suggests that spouses and children report caregiving in dementia differently with adult children seeing their parent with dementia less often yet reporting higher burden [42]. This may relate to greater worry experienced by being apart and additional external pressures such as the draw and demands of balancing work and their own personal life. While direct measures of income were not available in this study, indirect measures including educational levels and employment status were obtained. These items garner a higher response rate to questions on income and are acceptable, albeit imperfect alternatives [43]. Including these in regression models found that they were not associated with an increased odds of burden. This contrasts with other studies that have shown an association between lower income and caregiver burden [44].

In this sample, only DBRI scores reflecting BPSD were significantly associated with burden and only in those with dementia. Many of the traditional factors (demographic or personal characteristics) associated with burden were not significant in this sample. Hence, we suggest that BPSD should be considered, identified and where possible mitigated for as early as possible when patients present for assessment of cognition. BPSD and caregiver burden should be monitored for among carers of people with MCI attending these clinics too as it may in addition to decline in cognitive and functional test scores, signal conversion from MCI to dementia (i.e., it may act as another signal or sign of cognitive decline). The authors suggest that waiting to assess caregiver 
burden only among those caring for people with established dementia may miss an opportunity to intervene early and prevent it from worsening and resulting in poorer outcomes for these patients.

\section{Use of CSIs in identifying burden}

In this study both MoCA and Qmci screen scores correlated (negatively and statistically significantly) with caregiver burden. The $\mathrm{Q} m c i$ screen is a relatively new short CSI and has not previously been correlated with burden. The results suggest that low or falling Qmci screen scores (and others including the MoCA) should prompt the search for caregiver burden.

\section{Strengths and limitations}

The strengths of this study include the setting, namely a University hospital memory clinic, and the diversity of patients included across the spectrum of cognitive function including SCD and MCI. This study has a number of limitations. This was a clinical study that did not use biomarkers and hence it is possible that some patients may have been misclassified as having cognitive impairment. The sample size was modest and as participants were from a homogenous sample of largely Irish Caucasians, attending a single clinic, the results may be less generalizable. Further, most of the patients presenting to the clinic had dementia (67\%) and there is the potential for spectrum bias. A larger sample of patients with MCI is required to evaluate and compare the differential impact of the stage of cognitive decline on caregiver burden. Understanding this may also lead to future preventative interventions targeting caregivers of people with MCI before onset of more marked burden in those with dementia. Other similar studies to this paper have suggested that subtle cognitive deficits and impairment in functional deficits such as using technology and performance in social roles and engagements, which may not be sufficiently severe to result in patients being classified as having early stage dementia [45], may represent features of burden in MCI (e.g., those captured on the LawtonBrody Index) [46, 47]. These may lead to additional stress for both patients and caregivers and combined with symptoms such as frustration and verbal aggressiveness may lead to arguments that mark the beginning of caregiver burden. Other potential variables that should also be included in future studies include frailty, co-morbidities (e.g., Geriatric syndromes), and the number and type of medications including polypharmacy [46]. These conditions may lead to an increased burden of care (providing additional supervision and hands on care) and compound changes in cognition. Further as insufficient data were available on the characteristics of caregivers themselves, particularly no data were available on their own co-morbidities, mood, functional and cognitive status, these variables should also be examined in future research as well as the effect of different care networks (e.g., formal versus informal) and support structures available to mitigate carer burden [48]. Finally, no standardized approach to diagnosing caregiver burden was used, potentially over or underestimating prevalence. The abbreviated version of the $\mathrm{ZBI}$, the CBS, was used rather than the full ZBI score, which may have resulted in bias [23]. This said, the abbreviated six-item questionnaire has similar reliability and accuracy in diagnosing burden as longer versions $[23,38]$.

\section{CONCLUSIONS}

In conclusion, this study shows that the prevalence of caregiver burden among patients attending memory clinics including those with MCI is high. While several established risk factors were identified including the severity of functional and cognitive impairment and the characteristics of carers, only BPSD as measured with the DBRI was an independent predictor. The results suggest that clinicians working in memory clinics should focus on neuropsychiatric symptoms in patients with MCI and dementia and on managing caregivers' psychological distress to reduce carer burden. The severity of neuropsychiatric symptoms in this population may be inferred from CBS scores, which should prompt further assessment. The paper also highlights the importance of screening caregivers of patients presenting at all stages of cognitive decline not only for burden but also for grief and depression to identify those most likely to benefit from intervention. Further study examining the characteristics of carers and measures to address burden among caregivers attending with patients presenting to memory clinics is now required. Qualitative study should also be conducted to understand the experience of both patients and caregivers reporting burden to better understand this challenging consequence of providing care. Comparisons between formal and informal caregivers are also important. 


\section{CONFLICT OF INTEREST}

Prof. David William Molloy and Dr. Rónán O'Caoimh are copyright holders of the Qmci screen. The authors report no conflict of interest.

\section{REFERENCES}

[1] Russ TC, Stamatakis E, Hamer M, Starr JM, Kivimaki M, Batty DG (2012) Association between psychological distress and mortality: Individual participant pooled analysis of 10 prospective cohort studies. BMJ 345, e4933.

[2] Mahoney R, Regan C, Katona C, Livingston G (2005) Anxiety and depression in family caregivers of people with Alzheimer's disease: The LASER-Ad Study. Am J Geriatr Psychiatr 13, 795-801.

[3] Cooper C, Balamurali TB, Livingston B (2007) A systematic review of the prevalence and covariates of anxiety in caregivers of people with dementia. Int Psychogeriat 19, 175-195.

[4] Stites SD Largent EA, Johnson R, Harkins K, Karlawish J (2021) Effects of self-identification as a caregiver on expectations of public stigma of Alzheimer's disease. J Alzheimers Dis Rep 5, 31-39.

[5] Alfakhri AS, Alshudukhi AW, Alqahtani AA, Alhumaid AM, Alhathlol OA, Almojali AI, Alotaibi MA, Alaqeel MK (2018) Depression among caregivers of patients with dementia. Inquiry 55, 0046958017750432.

[6] Zarit, S, Orr, N, Zarit, J (1985) The Hidden Victims of Alzheimer's Disease: Families Under Stress. New York University Press, New York.

[7] Collins RN, Kishita N (2020) Prevalence of depression and burden among informal caregivers of people with dementia: A meta-analysis. Age Soc 40, 2355-2392.

[8] Kang HS, Myung W, Na DL, Kim SY, Lee JH, Han SH, Choi SH, Kim S, Kim S, Kim DK (2014) Factors associated with caregiver burden in patients with Alzheimer's disease. Psychiatr Invest 11, 152.

[9] Berger G, Bernhardt T, Weimer E, Peters J, Kratzch T, Frolich L (2005) Longitudinal study on the relationship between symptomatology of dementia and levels of subjective burden and depression among family caregivers in memory clinic patients. J Geriatr Psychiatr Neur 18, 119-128.

[10] Yu H, Wang X, He R, Liang R, Zhou L (2015) Measuring the caregiver burden of caring for community-residing people with Alzheimer's disease. PLoS One 10, e0132168.

[11] Brodaty H, Woodward M, Boundy K, Ames D, Balshaw R, PRIME Study Group (2014) Prevalence and predictors of burden in caregivers of people with dementia. Am J Geriatr Psychiatr 22, 756-765.

[12] Allen AP, Buckley MM, Cryan JF, Ní Chorcoráin A, Dinan TG, Kearney PM, O'Caoimh R, Calnan M, Clarke G, Molloy DW (2020) Informal caregiving for dementia patients: The contribution of patient characteristics and behaviours to caregiver burden. Age Ageing 49, 52-56.

[13] Seeher K, Low LF, Reppermund S, Brodaty H (2013) Predictors and outcomes for caregivers of people with mild cognitive impairment: A systematic literature review. Alzheimers Dement 9, 346-355.

[14] Paradise M, McCade D, Hickie IB, Diamond K, Lewis SJ, Naismith SL (2015) Caregiver burden in mild cognitive impairment. Aging Ment Health 19, 72-78.
[15] Hayashi S, Terada S, Nagao S, Ikeda C, Shindo A, Oshima E, Yokota O, Uchitomi Y (2013) Burden of caregivers for patients with mild cognitive impairment in Japan. Int Psychogeriatr 25, 1357-1363.

[16] Connors MH, Seeher K, Teixeira-Pinto A, Woodward M, Ames D, Brodaty H (2019) Mild cognitive impairment and caregiver burden: A 3-year-longitudinal study. Am J Geriatric Psychiatr 27, 1206-1215.

[17] O'Caoimh R, Timmons S, Molloy DW (2016) Screening for mild cognitive impairment: Comparison of "MCI specific" screening instruments. J Alzheimers Dis 51, 619-629.

[18] American Psychiatric Association (1994) Diagnostic and Statistical Manual of Mental Disorders, 4th edition. American Psychiatric Association, Washington, DC.

[19] Reisberg B (1988) Functional Assessment Staging (FAST). Psychopharmacol Bull 24, 653-659.

[20] Petersen RC, Smith GE, Waring SC, Ivnik RJ, Tangalos EG, Kokmen E (1999) Mild cognitive impairment: Clinical characterization an outcome. Arch Neurol 56, 303-308.

[21] Albert MS, DeKosky ST, Dickson D, Dubois B, Feldman HH, Fox NC, Gamst A, Holtzman DM, Jagust WJ, Petersen RC, Snyder PJ (2011) The diagnosis of mild cognitive impairment due to Alzheimer's disease: Recommendations from the National Institute on Aging-Alzheimer's Association workgroups diagnostic guidelines for Alzheimer's disease. Alzheimers Dement 7, 270-279.

[22] Paradise MB, Glozier NS, Naismith SL, Davenport TA, Hickie IB (2011) Subjective memory complaints, vascular risk factors and psychological distress in the middle-aged: A cross-sectional study. BMC Psychiatr 11, 108.

[23] Bédard M, Molloy DW, Squire L, Dubois S, Lever JA, O'Donnell M (2001) The Zarit burden interview: A new short version and screening version. Gerontologist 41, 652657.

[24] Coughlan P, O'Caoimh R, Gao Y, Molloy DW (2013) The Quick Memory Check development and validation of a "home" caregiver administered cognitive screen. Irish $J$ Med Sci 182, 215.

[25] Yesavage JA (1988) Geriatric depression scale. Psychopharmacol Bull 24, 709-711.

[26] Marc LG, Raue PJ, Bruce ML (2008) Screening performance of the Geriatric Depression Scale (GDS-15) in a diverse elderly home care population. Am J Geriatr Psychiatry 16, 914-921.

[27] Collin C, Wade D, Davies S, Horne V (1988) The Barthel ADL Index: A standard measure of disability? Int Disabil Stud 10, 64-67.

[28] Lawton MP, Brody EM (1969) Assessment of older people: Self-maintaining and instrumental activities of daily living. Gerontologist 9, 179e86.

[29] Cummings J, Mega M, Gray K, Rosenberg-Thompson S, Carusi DA, Gornbein J (1994) The Neuropsychiatric Inventory: Comprehensive assessment of psychopathology in dementia. Neurology 44, 2308-2314.

[30] Molloy DW, Bédard M, Guyatt GH, Lever JA (1996) Dysfunctional behaviour rating instrument. Int Psychogeriatr $\mathbf{8}$, 333-341.

[31] Nasreddine ZS, Phillips NA, Bedirian V, Charbonneau S, Whitehead V, Collin I, Cummings JL, Chertkow H (2005) The Montreal Cognitive Assessment, MoCA: A brief screening tool for mild cognitive impairment. J Am Geriatr Soc 53, 695-699.

[32] O'Caoimh R, Gao Y, McGlade C, Healy L, Gallagher P, Timmons S, Molloy DW (2012) Comparison of the Quick Mild Cognitive Impairment (Q $m c i)$ screen and the SMMSE 
in screening for mild cognitive impairment. Age Ageing 41, 624-629.

[33] O’Caoimh R, Gao Y, Gallagher P, Eustace J, McGlade C, Molloy DW (2013) Which part of the Quick mild cognitive impairment screen $(\mathrm{Q} m c i)$ discriminates between normal cognition, mild cognitive impairment and dementia? Age Ageing 42, 324-330.

[34] Molloy DW, Standish TIM (1997) A guide to the Standardized Mini-Mental State Examination. Int Psychogeriatrics 9, 87-94.

[35] Galvin JE, Rose CM, Powlishta KK, Coats MA, Muich SJ, Grant E, Miller JP, Storandt M, Morris JC (2005) The AD8. A brief informant interview to detect dementia. Neurology 65, 559-564.

[36] Jorm AF (1994) A short form of the Informant Questionnaire on Cognitive Decline in the Elderly (IQCODE): Development and cross-validation. Psychol Med 24, 145153.

[37] Arango Lasprilla JC, Moreno A, Rogers H and Francis K (2009) The effect of dementia patient's physical, cognitive, and emotional/behavioral problems on caregiver wellbeing: Findings from a Spanish-speaking sample from Colombia, South America. Am J Alzheimers Dis Other Demen 24, 384395.

[38] Stagg B, Larner AJ (2015) Zarit Burden Interview: Pragmatic study in a dedicated cognitive function clinic. Prog Neurol Psychiatry 19, 23-27.

[39] Stagg B, Larner AJ (2015) Zarit Burden Interview: A possible informant-based diagnostic test for dementia? Eur $J$ Neurol 22, 423.

[40] Read JR, Sharpe L, Modini M, Dear BF (2017) Multimorbidity and depression: A systematic review and meta-analysis. J Affect Disorders 221, 36-46.

[41] Fischer CE, Ismail Z, Schweizer TA (2012) Impact of neuropsychiatric symptoms on caregiver burden in patients with Alzheimer's disease. Neurodegen Dis Manage 2, 269-277.
[42] Rigby T, Ashwill RT, Johnson DK, Galvin JE (2019) Differences in the experience of caregiving between spouse and adult child caregivers in dementia with Lewy bodies. Innov Aging 3, igz027.

[43] Galobardes B, Shaw M, Lawlor DA, Lynch JW, Smith GD (2006) Indicators of socioeconomic position (part 1). J Epi Comm Health 60, 7-12.

[44] Andrén S, Elmståhl S (2007) Relationships between income, subjective health and caregiver burden in caregivers of people with dementia in group living care: A cross-sectional community-based study. Int J Nurs Stud 44, 435-446.

[45] Kamiya M, Sakurai T, Ogama N, Maki Y, Toba K (2014) Caregivers' burden in Alzheimer's disease. Geriatr Geront Int 14, 45-55.

[46] Brown PJ, Devanand DP, Liu X, Caccappolo E; Alzheimer's Disease Neuroimaging Initiative (2011) Functional impairment in elderly patients with mild cognitive impairment and mild Alzheimer disease. Arch Gen Psychiatry 68, 617-626.

[47] Dauphinot V, Ravier A, Novais T, Delphin-Combe F, Mouchoux C, Krolak-Salmon P (2016) Risk factors of caregiver burden evolution, for patients with subjective cognitive decline or neurocognitive disorders: A longitudinal analysis. J Am Med Dir Assoc 17, 1037-1043.

[48] O'Caoimh R, Cornally N, Svendrovski A, Weathers E, FitzGerald C, Healy E, O'Connell E, O'Keeffe G, O'Herlihy E, Gao Y, O'Donnell R, O'Sullivan R, Leahy-Warren P, Orfila F, Paúl C, Clarnette R, Molloy DW (2016) Measuring the effect of carers on patients' risk of adverse healthcare outcomes using the caregiver network score. J Frailty Aging $\mathbf{5}, 104-110$. 